\title{
Optimization of the sintering process of raw material wastes
}

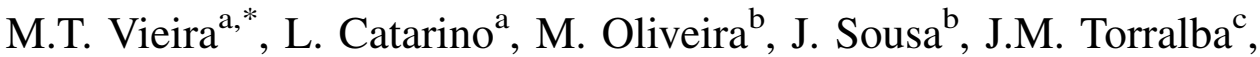 \\ L.E.G. Cambronero ${ }^{\mathrm{d}}$, F.L. González-Mesones ${ }^{\mathrm{d}}$, A. Victoria ${ }^{\mathrm{d}}$ \\ ${ }^{a}$ Dept. Engenharia Mecanica, ICEMS, Universidade de Coimbra, Pinhal de Marrocos, Coimbra 3030, Portugal \\ ${ }^{\mathrm{b}}$ Instituto Nacional de Engenharia e Tecnologia Industrial, Portugal \\ ${ }^{\mathrm{c}}$ Universidad Carlos III de Madrid, Spain \\ ${ }^{\mathrm{d}}$ Universidad Politécnica de Madrid, Spain
}

\begin{abstract}
The analysis of the mineralogical composition of most rock wastes shows the presence of a high percentage of minerals with $\mathrm{SiO}_{2}$ and $\mathrm{Al}_{2} \mathrm{O}_{3}$, which could be used as raw materials for ceramic products. The main objective of this work is to recover wastes from one primary rock industry, utilised in the production of tiles and flooring, for the manufacturing of ceramics, using powder technology: pressing and sintering. The sinterability of the powders, with and without previous heat treatment, was studied in order to obtain a product with the best performance. Powders from different quarries after being uniaxial pressed at $40 \mathrm{MPa}$, or isostatic pressed at $170 \mathrm{MPa}$ and sintered within the range $1150-1170^{\circ} \mathrm{C}$ present properties as follows: (a) hardness: 5.5-7.5 GPa; (b) transverse rupture strength: 55-94 MPa; (c) abrasion and erosion wear better than that of bulk to be drawn materials, and (d) water absorption of less than $0.5 \%$. The results allow the conclusion that these wastes can be recovered and used successfully in the manufacture of ceramics with better performance than traditional tiles and flooring. (C) 1999 Elsevier Science S.A. All rights reserved.
\end{abstract}

Keywords: Wastes; Powder technology; Ceramics

\section{Introduction}

During the manufacturing process of tiles and flooring from schist, from mining to their last machining operation, there are thousands of tons of wastes, which are presently unrecoverable. This creates several problems, involving the economic aspects of production (sometimes losses of over $50 \%$ of the raw material) and environmental aspects, i.e. thousands of tons of wastes usually end up in rivers or become part of the landscape as mountains of slurries.

Patents and open literature refer to the recovery process of these wastes in their direct application as additives of other products, or mixed with organic resins [1-4]. However, these applications are not enough for the enormous quantity of wastes produced in world quarries. The application of these wastes as raw material in the manufacturing of ceramic products could be a good alternative because it will mean greater consumption. For this to occur, it is important to study the thermal stability of the mineral components and to

*Corresponding author. Tel.: +351-39-790-700; fax: +351-39-790-701 E-mail address: teresa.vieira@mail.dem.uc.pt (M.T. Vieira) characterise the physical and mechanical behaviour of these complex materials.

Despite the great quantity of research work on the heat treatment of clays, little information is available concerning other raw materials from sedimentary and metamorphic rocks. The phase diagrams available [5] might be necessary information but are not sufficient for the understanding and establishment of sintering conditions. The aim of this research work is to optimise sintered schist wastes, taking into account the properties of the bulk material and those of traditional glazed tiles.

\section{Experimental}

The chemical composition of samples $\mathrm{P}$ and $\mathrm{G}$ (Table 1) were analysed using atomic absorption spectroscopy equipment, Perkin-Elmer 303, a UV/vis spectrophotometer, Perkin-Elmer $\lambda 2$, and an electron microprobe Cameca SX50 (EDAX). X-ray diffraction was the technique utilized to determine the mineralogical composition. In this case a Philips diffractometer Xpert was used with a heating capacity of up to $1400^{\circ} \mathrm{C}$ with an anticathode of cobalt 
Table 1

Chemical composition of the samples

\begin{tabular}{lcc}
\hline Oxides $(\%)$ & $\mathrm{P}$ & $\mathrm{G}$ \\
\hline $\mathrm{SiO}_{2}$ & $53.4-57.2$ & $53.9-79.8$ \\
$\mathrm{Al}_{2} \mathrm{O}_{3}$ & $23.9-26.8$ & $15.8-26.8$ \\
$\mathrm{Fe}_{2} \mathrm{O}_{3}+\mathrm{FeO}$ & $7.9-11.6$ & $5.4-10.8$ \\
Others oxides $^{\mathrm{a}}$ & $8.2-9.8$ & $8.7-6.8$ \\
Loss of ignition & $4.8-5.9$ & $7.3-6.9$ \\
\hline
\end{tabular}

${ }^{\mathrm{a}} \mathrm{TiO}_{2}, \mathrm{MnO}, \mathrm{MgO}, \mathrm{CaO}, \mathrm{Na}_{2} \mathrm{O}, \mathrm{K}_{2} \mathrm{O}, \mathrm{P}_{2} \mathrm{O}_{5}$.

$\left(\lambda \mathrm{K}_{\alpha 1}=1.78896 \AA, \lambda \mathrm{K}_{\alpha 2}=1.79285 \AA\right)$. To analyse the diffractograms the ICDC patterns were used. The samples were also analysed with optical microscopy and scanning electron microscopy (Jeol T 330). Some samples from $G$ were calcined at $1250^{\circ} \mathrm{C}$ and subsequently milled (these samples are identified as GC).The steps of the experimental procedure are summarised in Fig. 1. After sieving the samples under $100 \mu \mathrm{m}$, the powders of $\mathrm{P}$ and $\mathrm{G}$ samples were uniaxially compacted at $40 \mathrm{MPa}$ and the GC samples were cold isostatically pressed at $170 \mathrm{MPa}$. The green parts were sintered at temperatures between $1000^{\circ} \mathrm{C}$ and $1200^{\circ} \mathrm{C}$ in order to determine their sintering behaviour through densification. The apparent density was measured using the Archimedes method and employing a sealant in order to occlude open porosity and real density, through a helium picnometer.

The materials were tested mechanically: transverse rupture strength in a three-points bending test, hardness and wear resistance. The mechanical reliability of the transverse rupture strength, from the point of view of the Weibull modulus, was obtained through the method described by Molinari et al. [6]: 20 samples of dimensions $100 \mathrm{~mm}$ $\times 50 \mathrm{~mm} \times 3 \mathrm{~mm}$ were tested. The hardness of the materials was determined through the Mohs and Vickers scales. The materials that presented the best performance were subjected to the tests that are usually conducted on materials for construction: abrasion, erosion and water absorption. The abrasion test was conducted in accordance with the ASTM G 65-94 standard under the following conditions: speed of rotation, 200 r.p.m.; load, $130 \mathrm{~N}$; number of rotations, 2000;

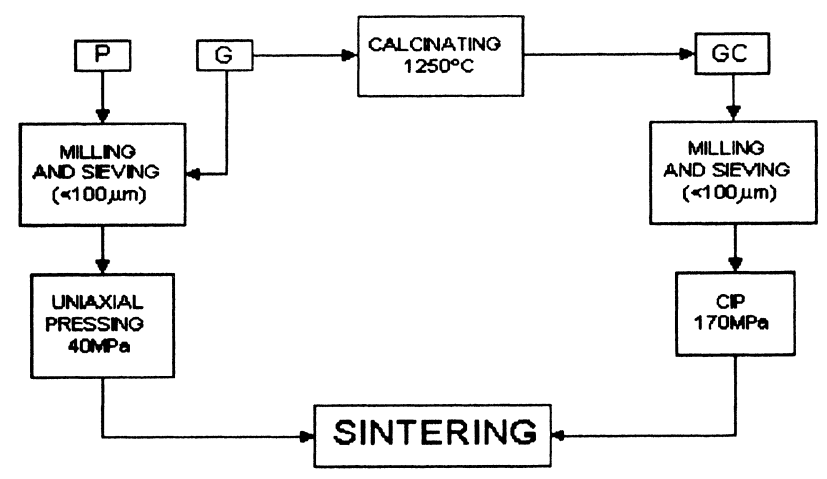

Fig. 1. Flow chart of the experimental process. diameter of the wheel, $226.3 \mathrm{~mm}$; width of the wheel, $13.6 \mathrm{~mm}$; abrasion flux, $400 \mathrm{~g} / \mathrm{min}$; the results were compared with those of 14 different glazed ceramics. The erosion test was carried out using Air Jet Erosion Test Mach, experimental equipment made by Falex Corporation. Alumina was used as an erosive in the experiment. Water absorption was measured using the standard project of European Norms 1339/96.

\section{Results}

The chemical analyses of schist are presented in Table 1 (wt\%). The principal components are silica, alumina and iron oxides. In Fig. 2 the variation of the density as a function of the sintering temperatures is shown. In the $\mathrm{P}$ and $\mathrm{G}$ samples, the results for temperatures of up to $1150^{\circ} \mathrm{C}$ are similar.

The transverse rupture strengths as a function of the sintering temperatures are shown in Fig. 3 and their reliability under the Weibull modulus parameter in Fig. 4. P, G and GC samples present the same value when sintered at $1150^{\circ} \mathrm{C}(80 \mathrm{MPa})$. At a sintering temperature of $1170^{\circ} \mathrm{C}$, the bending strengths are maximal for $\mathrm{P}$ and $\mathrm{G}$. However for the previously heat-treated samples, the bending strength decreases significantly with temperatures higher than

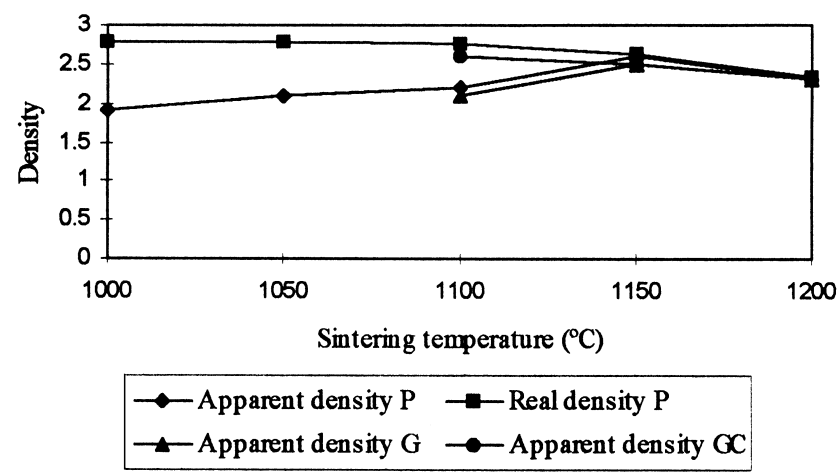

Fig. 2. Sinterability of the P, G and GC materials.

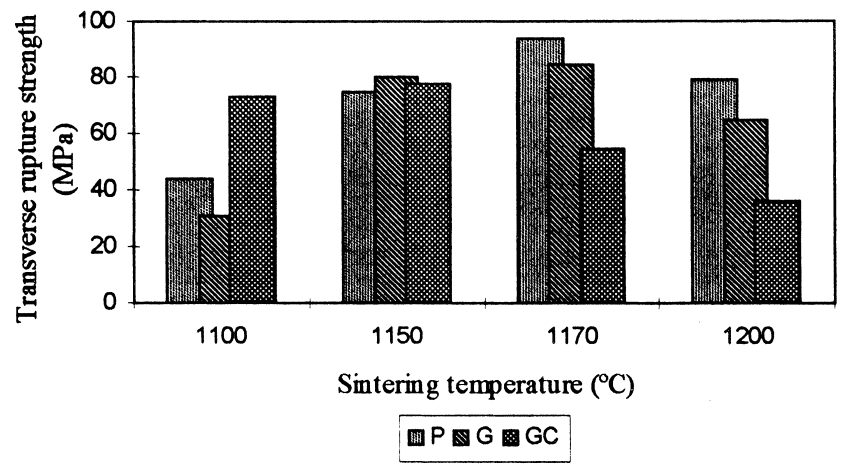

Fig. 3. Transverse rupture strength of sintered P, G and GC materials for different sintering temperatures. 


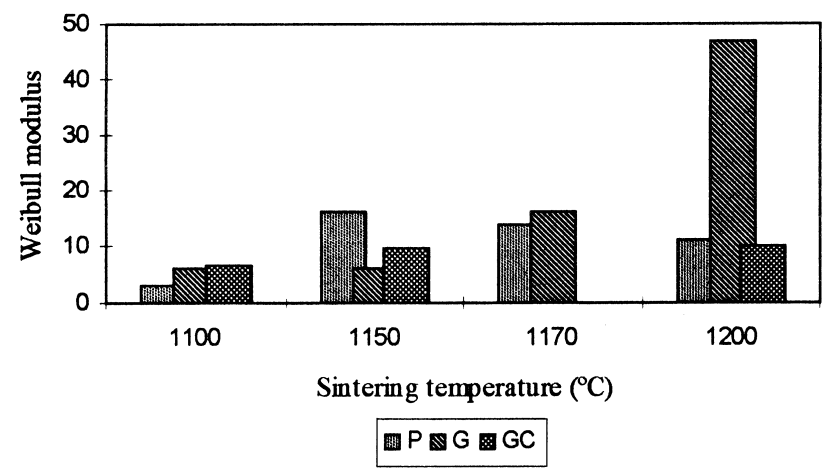

Fig. 4. Weibull modulus of sintered P, G and GC materials for different sintering temperatures.

$1150^{\circ} \mathrm{C}$. Also, after sintering at $1150^{\circ} \mathrm{C}$, the Weibull modulus is normally higher than 10 .

The variation of the Vickers hardness with sintering temperatures (Fig. 5) shows a maximum hardness at $1100^{\circ} \mathrm{C}$ for $\mathrm{P}$ samples and $1150-1200^{\circ} \mathrm{C}$ for $\mathrm{G}$ samples. In the Mohs scale the values for those temperatures are 7-8 hardness.

Figs. 6 and 7 show the results related to the wear behaviour of the materials under study. The comparison of the abrasion test results of the materials studied with those of 14 different ceramic glazed flooring tiles $(\mathrm{T})$ are presented in Fig. 6. Fig. 7 reports the erosion rate of the $\mathrm{P}$ materials in

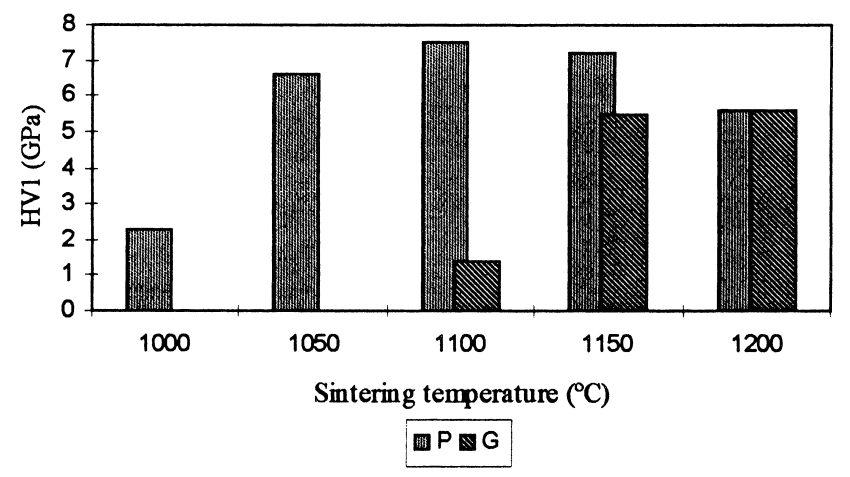

Fig. 5. Vickers hardness of sintered $P$ and $G$ materials for different sintering temperatures.

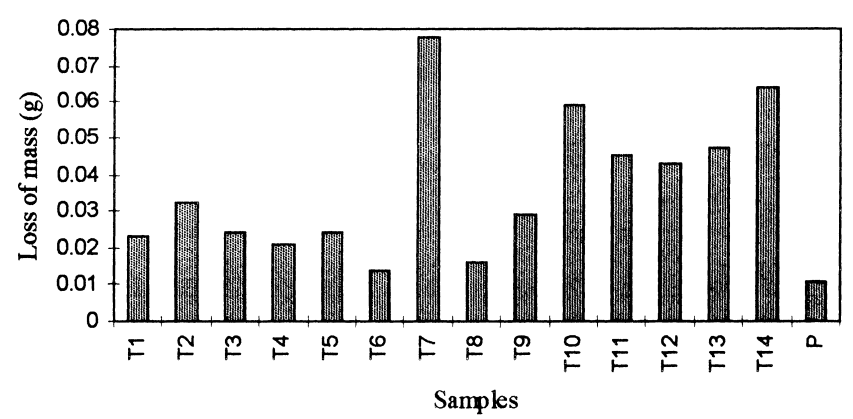

Fig. 6. Abrasion results comparing sintered $\mathrm{P}$ materials with different ceramic flooring tiles $(\mathrm{T})$.

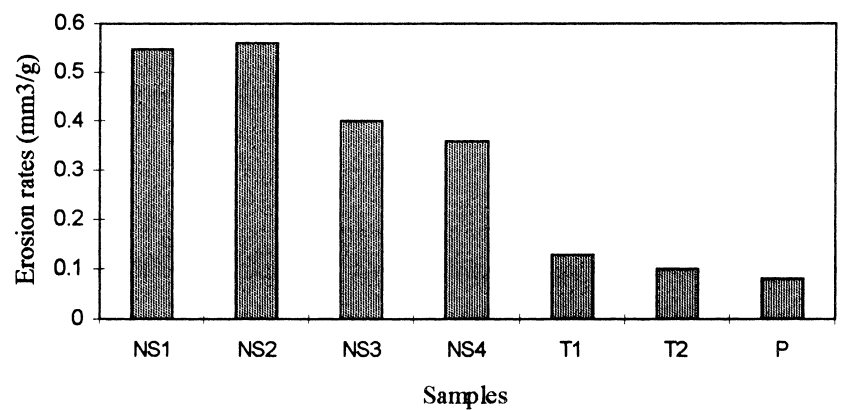

Fig. 7. The erosion rate of sintered $\mathrm{P}$ materials in comparison with those of natural stone (NS) and ceramic flooring tiles (T).

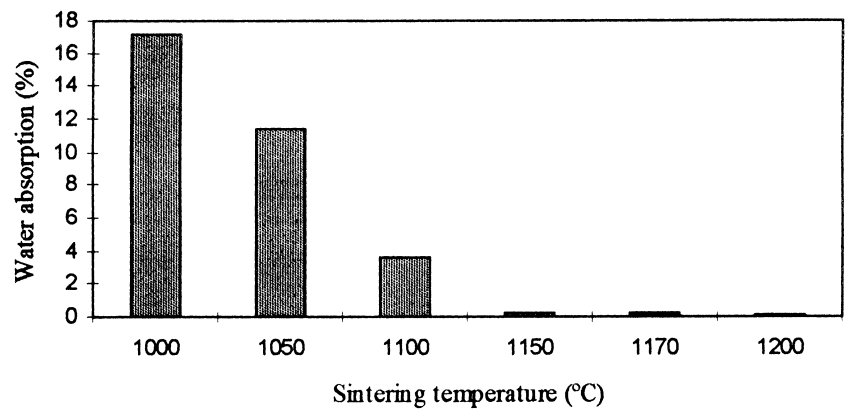

Fig. 8. Water absorption of sintered $\mathrm{P}$ materials for different sintering temperatures.

comparison with that of natural stone (NS) often used as paving, and two ceramic flooring tiles $(\mathrm{T})$. In both cases the recovery product presents the best properties.

The results concerning the test of water absorption in $\mathrm{P}$ materials as a function of sintering temperature shows that for a sintering temperature of $1150-1200^{\circ} \mathrm{C}$ the water absorption is nearly zero (Fig. 8).

\section{Discussion}

Taking into account the experimental results, it can be affirmed that samples densify easily for densities up to as close as $90 \%$ of the theoretical density 1 . Using this as the main parameter, and looking at Fig. 2, these materials densify even at low temperatures $\left(1100^{\circ} \mathrm{C}\right)$, considering the temperature at which conventional ceramics are fired. Thus one can deduce that these wastes can be processed just like ceramic materials.

In reality, the detailed study undertaken on structural phase transformations occurring in those materials as a function of temperature enabled the determination, through the analysis of the results of X-ray diffraction (Figs. 9-11) and chemical analysis by EDAX, the irreversible formation of hercynite, mullite and amorphous silica at above $1100^{\circ} \mathrm{C}$. The irreversibility of the transformations that occur during the treatment at higher temperatures is shown also by the unchangeability of the X-ray diffractogram obtained at a 

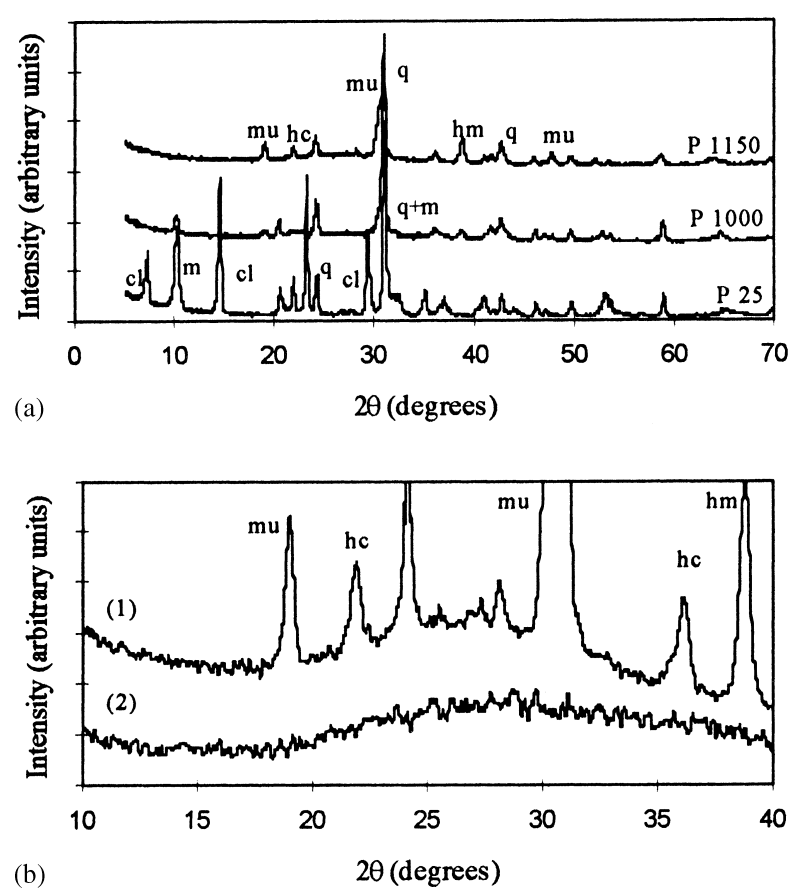

Fig. 9. (a) X-ray diffraction of $\mathrm{P}$ materials at different temperatures $(\mathrm{q}-$ quartz; $\mathrm{m}$ - mica; cl - chlorite; mu - mullite; hc - hercynite; hm - hematite). (b) Details of the P1150 diffractogram (1) and amorphous silica as standard (2)
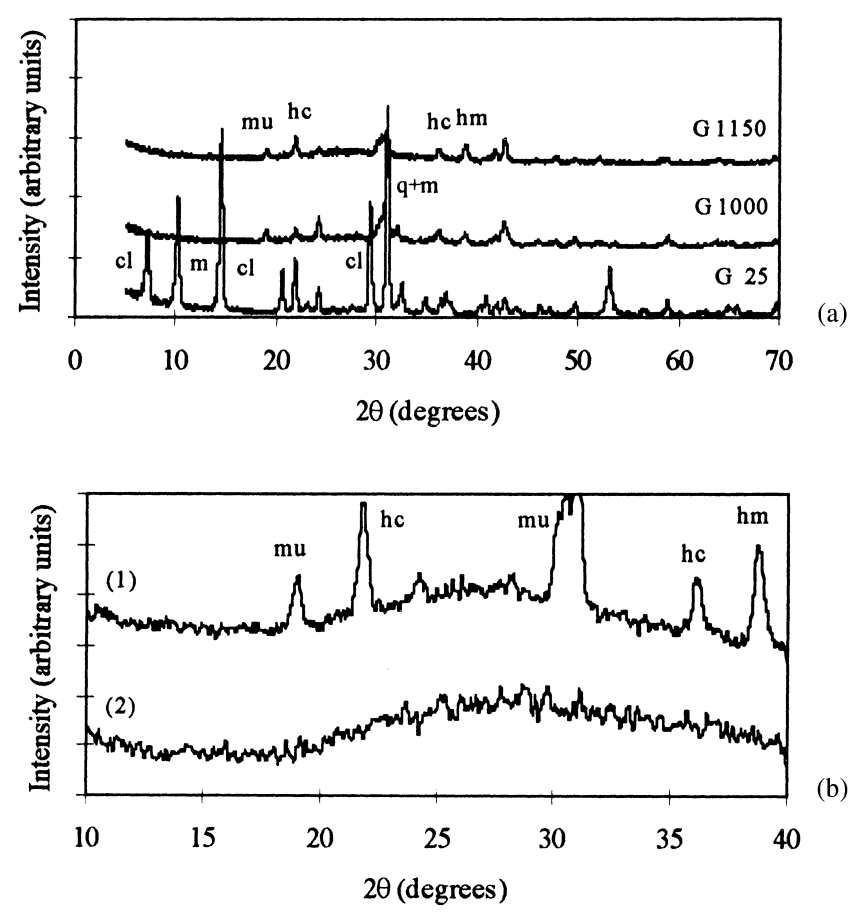

Fig. 10. (a) X-ray diffraction of $\mathrm{G}$ materials at different temperatures (qquartz; m - mica; cl - chlorite; mu - mullite; hc - hercynite; hm hematite). (b) Details of the G1150 diffractogram (1) and amorphous silica as standard (2).

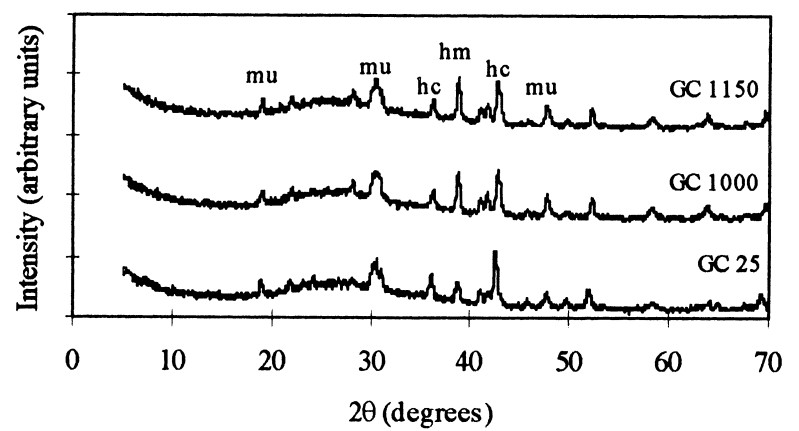

Fig. 11. X-ray diffraction of GC materials at different temperatures (mu mullite; hc - hercynite; hm - hematite).

high temperature and also by those resulting from GC materials, previously treated at $1250^{\circ} \mathrm{C}$ (Fig. 11). The quantity of these phases is higher as the treatment temperature increases. During the evaluation of hardness, it was noted that at particular locations, the hardness values were significantly higher than the mean value (>10 GPa), which could be due to the presence of a very hard phase, spread over the matrix, that could be related to mullite. However, the SEM observation and the evaluation of the chemical composition by EDAX is not sufficiently clear in the identification of how these phases are distributed in the samples. For example at $1200^{\circ} \mathrm{C}$ the chemical analysis performed on different points of the sample only reveals three different typical chemical compositions: $3(\mathrm{Al}, \mathrm{Fe})_{2} \mathrm{O}_{3} \cdot \mathrm{SiO}_{2}$; $(\mathrm{Al}, \mathrm{Fe})_{2} \mathrm{O}_{3} \cdot \mathrm{SiO}_{2}$, which could be interpreted as two types of mullite or a mixture of mullite and hercynite; and $\mathrm{FeAl}_{2} \mathrm{O}_{3}+\mathrm{SiO}_{2}$ as hercynite with silica. These are not attached to a special phase micrography and could be present at close points of the same "phase".

The increase of amorphous silica with sintering temperature (Figs. 9 and 10) enables the conclusion that this phase serves as a binder, lodging into the pores available between the granules of the material, and being responsible for the increase in the mechanical behaviour of the samples, and the decrease in water absorption. In fact, from the studies undertaken on the absorption of water as a function of thermal treatment (Fig. 8) it can be concluded that the absorption only decreases significantly when the temperature during the treatment reaches a level higher than $1100^{\circ} \mathrm{C}$, meaning after the clear formation of the amorphous phase.

Therefore, the mechanical behaviour of the heat-treated samples serves to prove that whilst the amorphous phase plays an important role in the densification process, mullite and hercynite can also play an active role in the process, although this is yet to be demonstrated.

The initially constant values of the mechanical resistance of the previously heat-treated samples (GC) show that this behaviour is related to phase transformations that occurred during the previous roasting. In fact, taking into consideration Fig. 11, it is verified that after previous heat-treatment, the phases present are similar to those that occurred during 
the sintering of the $\mathrm{P}$ and $\mathrm{G}$ samples $\left(>1000^{\circ} \mathrm{C}\right)$. However, the degradation of the bending strength for high values of sintering temperature, which can be related to an excess of the formation of silica during sintering, can be verified as being related to the temperatures of the treated powders. In effect, the excess of a fragile phase in the ceramic material could be responsible for the decrease in its mechanical properties.

Properties related to mechanical behaviour such as hardness, transverse rupture strength, abrasion and erosion wear, show higher values of reliability when compared with those of other traditional glazed ceramic products $[7,8]$. The excellent Weibull modulus should be highlighted, particularly for samples treated at $1150^{\circ} \mathrm{C}$, especially when considering the Weibull modulus of 10 , which is the goal for what are called advanced ceramics $[9,10]$.

\section{Conclusions}

The technical properties of recovery wastes in relation to those of natural stone or other glazed or non-glazed traditional ceramics, are highly favourable. All of these properties reveal that the new materials have a wide range of applications and are highly competitive with most traditional ceramics presently on the market.

\section{Acknowledgements}

This work has been undertaken thanks to the financial support of the European Union through the project CRAFT BRST CT95-0063.

\section{References}

[1] 90:17234 USPAT, Treatment of expansible materials to form lightweight aggregate.

[2] 88:13045 USPAT, Treatment of expansible materials to form lightweight aggregate.

[3] EP 20102 A1, Improvements in methods of manufacturing building products from moulding compositions.

[4] M.A. Rodríguez, F. Rubio, J. Rubio, M.J. Liso, J.L. Oteo, Composites de poliéster reforzados con pizarras, Materiales Compuestos 95, 1995.

[5] E.M. Levin, C.R. Robbins, H.F. McMurdie, Phase Diagrams for Ceramists, American Ceramic Society, 1964.

[6] A. Molinari, A. Tiziani, B. Tesi, G. Straffelini, in: Advances in Powder Metallurgy, vol. 4, Metal Powder Industries Federation, Princeton, NJ, 1991, pp. 159-182.

[7] W.E. Lee, W.M. Rainforth, in: Ceramic Microstructures, Chapman and Hall, 1994.

[8] Brochure of Ceramiques Techniques Desmarquest (Pechiney Group), F-78190 Trappes, France.

[9] A. Benett, Mater. Sci. Tech. 2 (1986) 895-899.

[10] K. Kendall, S.R.McN. Alford, J.D. Birchall, J. Mater. Res. 1 (1986) 120-126. 